\title{
Reciprocal antimicrobial synergism between Escherichia coli and Bacteroides fragilis in the presence of metronidazole
}

\author{
F SORIANO, MC PONTE, MC GASPAR
}

From the Department of Microbiology, Jiménez Díaz Foundation, Autonomous University, Av. Reyes Catolicos 2, Madrid 3, Spain

SUMMARY We have studied the antimicrobial action of metronidazole against Bacteroides fragilis and Escherichia coli both in pure cultures and in combination. Concentrations of metronidazole above the minimal inhibitory concentration (MIC) produced a marked bactericidal effect on $B$ fragilis at six hours. $E$ coli however showed only a slight and transitory decrease in population when exposed to concentrations of metronidazole close to its MIC. Kinetic studies of this drug's effect on mixed cultures of both organisms showed mutual bactericidal synergy between $E$ coli and metronidazole against $B$ fragilis and between $B$ fragilis and metronidazole against $E$ coli. These in vitro findings agree with the results obtained in vivo by other authors.

It has been shown that metronidazole reduces mortality from experimental peritonitis induced in rats by inoculation of caecal content or mixtures of facultative and anaerobic bacteria from the gut. ${ }^{1}$ It has been suggested that metronidazole may possess an antimicrobial effect not only against anaerobic bacteria, especially Bacteroides fragilis, but also against aerobic and facultative organisms, although the results published are to a certain extent contradictory. ${ }^{1-5}$ While it has been shown that certain strains of Escherichia coli are, in specific experimental conditions, susceptible to metronidazole,$^{3}$ there is much doubt as to interaction between this drug and the mixed flora of the gut.

The antimicrobial action of metronidazole against anaerobes and possibly aerobic and facultative bacteria also is an important feature of this drug and one that is not shared by others chemically unrelated to it but highly active against certain anaerobes like clindamycin. ${ }^{1}$

Most of the literature on metronidazole, E coli and $B$ fragilis interaction has been mainly concerned with the drug's effect on $E$ coli. This paper studies the kinetic effect of metronidazole on both $E$ coli and $B$ fragilis as well as the interaction of these three variables in an in vitro system.

\section{Material and methods}

BACTERIAL STRAINS

One freshly isolated strain of $B$ fragilis and another of $E$ coli were studied. Their anaerobic minimal inhibitory concentration (MIC) were 1 and $64 \mu \mathrm{g} / \mathrm{ml}$ of metronidazole, respectively.

\section{CULTURE MEDIUM}

An EBB medium was used. This consisted of brucella broth (Difco) enriched with sodium bicarbonate $(11.9 \mathrm{mmol} / \mathrm{l})$, hemin (Sigma) $(7.67$ $\mu \mathrm{mol} / \mathrm{l})$, and menadione (Sigma) $(1.16 \mu \mathrm{mol} / \mathrm{l})$. The final $\mathrm{pH}$ was $7 \cdot 3$.

\section{INOCULUM}

The bacteria were inoculated in anaerobiosis using the GasPak (BBL) system at $35^{\circ} \mathrm{C}$ for $24 \mathrm{~h}$. One drop of Pasteur pipette from a 24 hour-culture was added to a tube containing $10 \mathrm{ml}$ of EBB medium without drug, and to three others containing respectively 4,16 and $64 \mu \mathrm{g} / \mathrm{ml}$ of metronidazole (Rhodia Iberica) in the same medium. The bacteria were placed in pure culture and, in another experiment, mixed equally in order to obtain $10^{6}$ to $10^{7} \mathrm{CFU} / \mathrm{ml}$ in every case.

\section{KINETIC STUDY}

Colony forming units of the two organisms were counted at $0,6,24$ and $52 \mathrm{~h}$ using dilutions of their 
Effect of metronidazole on pure and mixed cultures of Escherichia coli and Bacteroides fragilis

\begin{tabular}{|c|c|c|c|c|c|c|c|c|}
\hline \multirow[t]{3}{*}{ Culture, time $(h)$} & \multicolumn{8}{|c|}{ Metronidazole concentration $(\mu \mathrm{g} / \mathrm{ml})$} \\
\hline & \multicolumn{2}{|l|}{0} & \multicolumn{2}{|l|}{4} & \multicolumn{2}{|l|}{16} & \multicolumn{2}{|l|}{64} \\
\hline & $\begin{array}{l}E c o \\
\left(\log _{1}\right.\end{array}$ & $\begin{array}{l}B \text { fragilis } \\
n l)\end{array}$ & $\begin{array}{l}E \text { coli } \\
\left(\log _{10} C F U / m\right.\end{array}$ & l) $B$ fragilis & $\begin{array}{l}E \text { coli } \\
\left(\log _{10} C F U / m l\right)\end{array}$ & b fragilis & $\begin{array}{l}E \text { coli } \\
\left(\log _{10} C F U / m l\right)\end{array}$ & b fragilis \\
\hline \multicolumn{9}{|l|}{ E coli } \\
\hline 0 & $7 \cdot 2$ & - & $6 \cdot 8$ & - & $6 \cdot 8$ & - & $6 \cdot 8$ & - \\
\hline 6 & 9 & - & 8 & - & 7.7 & - & $6 \cdot 6$ & - \\
\hline 24 & $9 \cdot 2$ & - & $>8$ & - & $7 \cdot 5$ & - & $6 \cdot 1$ & - \\
\hline $\begin{array}{l}52 \\
B \text { fragilis }\end{array}$ & & - \\
\hline 0 & - & $7 \cdot 3$ & - & $6 \cdot 8$ & - & $6 \cdot 8$ & - & $6 \cdot 8$ \\
\hline 6 & - & $8 \cdot 1$ & - & 6.8 & - & $5 \cdot 8$ & - & $6 \cdot 4$ \\
\hline 24 & - & $9 \cdot 6$ & - & $<3$ & - & $<3$ & - & $<3$ \\
\hline \multicolumn{7}{|l|}{$E$ coli $+B$ fragilis } & & $<3$ \\
\hline 0 & 6.9 & $7 \cdot 2$ & $6 \cdot 3$ & 6.6 & $6 \cdot 3$ & $6 \cdot 6$ & $6 \cdot 3$ & $6 \cdot 6$ \\
\hline 6 & 9 & $8 \cdot 1$ & $>8$ & $<3$ & $8 \cdot 2$ & $<3$ & 7 & $<3$ \\
\hline 24 & $9 \cdot 2$ & $9 \cdot 3$ & $>8$ & $<3$ & $7 \cdot 4$ & $<3$ & $5 \cdot 2$ & $<3$ \\
\hline 52 & $9 \cdot \overline{1}$ & 8.9 & $>8$ & $<3$ & $7 \cdot 6$ & $<3$ & $7 \cdot \overline{6}$ & $<3$ \\
\hline
\end{tabular}

respective broths, subcultures with calibrated loop on blood agar and blood-amikacin agar plates for differential colony-counts analysis. All experiments were repeated three times.

\section{Results}

The Table shows the number of colony forming units $\left(\log _{10}\right)$ per ml of the medium and the growth of $E$ coli and $B$ fragilis in pure and mixed cultures, both with and without metronidazole.

The first column gives the growth of the two bacteria without metronidazole in pure and mixed cultures. Growth is exponential, reaching a maximum at $24 \mathrm{~h}$. Growth within the same system of the two microorganisms showed no interference and in both cases the rate was similar to that shown when they grew in pure culture.

The second, third and fourth columns give the results obtained when the cultures, isolated and combined were exposed to 4,16 , and $64 \mu \mathrm{g} / \mathrm{ml}$ of metronidazole. The growth rate of $E$ coli did not change when it was exposed to $4 \mu \mathrm{g} / \mathrm{ml}$ of the drug either in pure culture or in combination with $B$ fragilis. The latter, however, was killed when exposed to $4 \mu \mathrm{g} / \mathrm{ml}$ of the drug after six hours but much more rapidly when exposed in combination with $E$ coli.

Concentrations of $16 \mu \mathrm{g} / \mathrm{ml}$ of metronidazole produced, at $24 \mathrm{~h}$ a very slow increase in the $E$ coli population growing in pure culture as compared with the control unexposed to the drug while $B$ fragilis already showed a slight drop at six hours and a much greater one at $24 \mathrm{~h}$. The same concentration of metronidazole proved much more bactericidally effective against $B$ fragilis when this organism was mixed with $E$ coli than when in pure culture.
Finally, $64 \mu \mathrm{g} / \mathrm{ml}$ of metronidazole was markedly bactericidal against $B$ fragilis but only very slightly against $E$ coli growing in pure cultures. This effect of metronidazole was observed after six hours' exposition with peak action at $24 \mathrm{~h}$. However, when the drug was added to a mixed culture of $B$ fragilis and $E$ coli, rapid and intense bactericidal action was observed at the sixth hour in the case of $B$ fragilis and at $24 \mathrm{~h}$ against $E$ coli, the population of the latter dropping from $10^{7}$ to $1.5 \times 10^{5} \mathrm{CFU} / \mathrm{ml}$ between the sixth and twenty-fourth hour of exposition. $E$ coli was later able to resume growth, since at $52 \mathrm{~h}$, bacterial density was twenty times higher than that of the initial inoculum. This population was not reexposed to metronidazole to discover whether it had acquired resistance to this drug.

Metronidazole showed intense bactericidal activity against $B$ fragilis at the twenty-fourth hour of exposition at all the concentrations (higher than the MIC) tested. $E$ coli showed a population decrease only when subjected to high concentrations of metronidazole, 16 and especially $64 \mu \mathrm{g} / \mathrm{ml}$ (study in anaerobiosis showed the latter figure to be its MIC).

Metronidazole was found to be not only more intensely but also more rapidly bactericidal, both against $B$ fragilis and $E$ coli in mixed that in pure cultures.

\section{Discussion}

$E$ coli and $B$ fragilis and metronidazole have been seen to be strongly interactive. $E$ coli-metronidazole synergy against $B$ fragilis has been little studied and the published data present a somewhat contradictory picture. ${ }^{1-367}$

Our study shows that the strain of $E$ coli used was susceptible in vitro to high concentrations of met- 
ronidazole (16 and particularly $64 \mu \mathrm{g} / \mathrm{ml}$ ) in anaerobiosis. This effect was only moderate and transitory since, after $24 \mathrm{~h}$, the bacteria resumed growth. These results agree with the finding of other authors $^{3}$ and $E$ coli may be susceptible to the drug in specific experimental conditions.

Analysis of the interaction of $E$ coli, $B$ fragilis and metronidazole showed mutual synergy between $E$ coli and metronidazole against $B$ fragilis and between $B$ fragilis and metronidazole against $E$ coli.

The bactericidal effect of metronidazole on $B$ fragilis combined with $E$ coli took place before six hours, much earlier therefore, than when the drug acted upon a pure culture of the anaerobe. It has been shown that in certain experimental conditions $E$ coli is capable of raising the levels of biologically active metronidazole, but that in the presence of $B$ fragilis the increase is slight and slow, ${ }^{1}$ which may be due to overconsumption of the drug. These results contrast with the findings of other authors who have observed the action of metronidazole against Entamoeba histolytica ${ }^{2}$ and Trichomonas vaginalis ${ }^{5}$ to be reduced when bacteria are present in the same system.

The antimicrobial action of metronidazole against $E$ coli combined with $B$ fragilis was greater than when the former was exposed to the drug in pure culture. The effect also depended on the concentration of metronidazole used and was greatest with 64 $\mu \mathrm{g} / \mathrm{ml}$ in the presence of $B$ fragilis. Although it has been said that $E$ coli is resistant to metronidazole, ${ }^{24-6}$ in certain experimental conditions, as when anaerobes are present in the same system, this microorganism may be much more sus- ceptible than it is when exposed in pure culture. Our in vitro findings largely agree with the results obtained in vivo by other authors. ${ }^{1}$

\section{Addendum}

After this paper was submitted for publication, we have noted work by Ingham et al (J Antimicrob Chemother 1981;8:475-9) showing that $E$ coli reduces the $\mathrm{PO}_{2}$ of the medium, thereby enhancing the activity of metronidazole against $B$ fragilis.

\section{References}

' Onderdonk AB, Kasper DL, Mansheim BJ, et al. Experimental animal models for anaerobic infections. Rev Infect Dis 1979;1:291-301.

${ }^{2}$ Edwards DI, Thompson EJ, Tomusange J. Inactivation of metronidazole by aerobic organisms. J Antimicrob Chemother 1979;5:315-6.

${ }^{3}$ Ingham HR, Hall CJ, Sisson PR, Tharagonnet D, Selkon, JB. Inactivation of metronidazole by aerobic organisms. $J$ Antimicrob Chemother 1979;5:734-5.

4 Salem AR, Jackson DD, McFadzean JA. An investigation of interactions between metronidazole (Flagyl) and other agents. $J$ Antimicrob Chemother 1975;1:387-90.

${ }^{5}$ Das SR, Ghoshal S. Reduction of amoebicidal activity of metronidazole (Flagyl) by bacteria. Curr Sci 1979;48:69-70.

- Ralph ED, Clarke DA. Inactivation of metronidazole by anaerobic and aerobic bacteria. Antimicrob Agents Chemother 1978;14:377-83.

' Chrystal EJT, Koch RL, McLafferty MA, Goldman P. Relationship between metronidazole metabolism and bactericidal activity. Antimicrob Agents Chemother 1980;18:566-73.

Requests for reprints to: Dr F Soriano, Department of Microbiology, Jiménez Díaz Foundation, Autonomous University, Av. Reyes Católicos 2, Madrid 3, Spain. 